\title{
THE CORRELATION BETWEEN DRAW LABEL CAPTION (DLC) AND DRILL TECHNIQUE TOWARD ENGLISH WRITING ABILITY
}

\author{
Fitri Palupi Kusumawati \\ Universitas Muhammadiyah Metro, Indonesia \\ fitripalupi_85@yahoo.com
}

\begin{abstract}
Writing ability is one of the important parts that should be learnt in the school. Writing can be said that it is very important for the students, because the students can express their ideas and cxperience in writing form. The teachers should always look for which one suitable technique to be applied to the students, in order to make the students interested in learning writing, they are Draw-Label-Caption (DLC) and Drill Technique. In this research, the researcher will compares DLC and Drill techniques that are the most effective technique to improve the students' writing ability.

In this experimental research, there are 3 variables. That are 1). Draw-Label-Caption (DLC) technique as the first independent variable. 2). Drill technique as the second independent variable. 3) Writing skill as the dependent variable. The method that is used in this research is test. Students are asked to write the text in English based on predetermined theme. In this study, researcher uses pre-test and post-test. Based on the data analysis the researcher gets the result of Based on the calculation, it is found that: 1) $F_{\text {ratio }}=7,5$ and $F_{\text {table }}$ at significance level $1 \%$ is 7,08 and at significance $5 \%$ is 4,00 . At this point the researcher finds that $F_{\text {ratio }}$ is bigger than $F_{\text {table. The researcher concludes that there is }}$ difference of students' English writing ability through DLC and Drill technique. 2) $\mathrm{F}_{\text {ratio }}=$ 37,7 at the same signifficance level. So there is difference of students' English writing ability through DLC and Drill technique.
\end{abstract}

Keywords: draw label caption (DLC), drill, writing descriptive text.

\section{INTRODUCTION}

English is a foreign language that is widely used by international country. Nowadays English in Indonesia is really needed, not only for communication but also for educational side and the other sides. English education is very important for all students from basic school until universities. Besides English is as international language and as communication tool, central characteristic and intellectual development, social and emotional student form the success in learning. There are basic four skills in learning English that have to be mastered well. Those are listening, speaking, reading and writing. In this opportunity, the writer will discuss about writing. Writing ability is one of the important parts we should learn in the school. With the exception of speaking, writing is the most popular and prevalent method of creating connections among people. As a means of building link between individuals and within communities, writing serves as the flexible foundation for almost every type of communications media. Based on the statements, writing can be said that it is very important for the students, because the students can express their ideas and experience in writing form.

At the Education Curriculum in High School arranged writing standards competencies that require students to express information in various forms of paragraphs. Learning to write essays with the pattern of paragraph development descriptions in English is one of the basic competencies of students who should be 
implemented, but in achieving success, both process and product, which is in accordance with the minimum completeness criteria is not easy.

Academic writing begins at the knowledge level of the audience and increases their learning. More than reporting information, writing to educate explains the meanings of personalities, locations, events, objects and concepts. The educational writer studies audiences to meet their intellectual expectations. Researching with accuracy keeps this type of writing interesting and fair.

Since writing ability is an important aspect in language teaching and learning, teacher should continue developing some techniques in teaching writing that can help students to raise and master their writing ability especially in descriptive genre. Being a good writer the students should have ability to master the genres.

In education sector, it is true that the basic problem is to give an enough time and suitable method for every student. These two things which become difficulties source in a classical system to reach mastery learning level. The limit of level minimum of mastery this material, sometimes become a basic standard passing for students who study about that.

Based on initial observations, the success of the process has not can be shown for the active participation of students in the class is still relatively low. There are some problems for students in making writing. These problems include: first, low interest of students towards learning to write English, writing student learning activities tend to be low. Second, the inability of students in the pouring and develop an idea or ideas in writing, results essay is not very innovative. It causes the difficulty of each student to develop an idea or the idea of the mind. Third, the inability of students for organizing sentences to be a meaningful writing. The last, the students have not skilled in sentences, limited understanding, and good grammar and English vocabulary. The problem not only comes from the students, but also for the teachers. Most of the teachers still use a conventional method which make student uninterested with the subject, especially for writing skill. It can be seen in the table below.

Table 1 : Data of Writing Descriptive Text ot the First Semester of Civil Engineering Students of UM Metro, Academic Year 2016/2017.

\begin{tabular}{|l|l|l|l|}
\hline Score & Range & Percentage & Remark \\
\hline A & $8-10$ & $10 \%$ & High \\
\hline B & $6-7,9$ & $20 \%$ & Medium \\
\hline C & $4-5,9$ & $70 \%$ & Low \\
\hline Sum & & $100 \%$ & \\
\hline
\end{tabular}

Source: English Lecturer at Civil Engineering Study Program of UM Metro

For the reasons above, the researcher decides to do the research of descriptive text. Since writing descriptive is considered difficulties to be mastered by the students, the teachers should always look for which one suitable technique to be applied to the students, in order to make the students interested in learning writing. The researcher would like to compare Draw-Label-Caption (DLC) and Drill Technique in order to find which technique is more effective in students' writing ability in descriptive text. 
Draw-Label-Caption (DLC) technique is the both a lesson plan and pre-writing technique that can help the students brainstorm before writing a description. It can also be used to introduce new vocabulary or review vocabulary. The basic technique is those students draw a picture, then label everything in the picture and then give an overall caption or summary of what is showing in the picture.

Drill is mechanical ways if getting students to demonstrate and practice their ability to use in specific language items in controller manner (Harmer, 2003:3). This technique can make students be easier to understand and mastered Descriptive Text namely; formatting, punctuation, generic structure, content, and grammar.

To sum up, the researcher wants to analyze about the comparison of using Draw Label Caption (DLC) and Drill technique toward students' writing ability in descriptive text at second semester students of Civil Engineering Study Program of Muhammadiyah University Metro. The researcher assumes that different techniques can give different sense in learning process, the teacher to increase students' skills, especially in writing descriptive text, can try it. Therefore, the researcher decides to choose those techniques as the research.

\section{LITERATURE REVIEW}

Concept of Technique

According Anthony (1963, p.7) technique is implementation, that which actually takes place in a classroom. It is a particular trick, strategy, or contrivance used to accomplish an immediate objective. Technique must be consistent with a method and therefore in harmony with an approach as well. Technique is a learning activity that should be done by the teacher or student in order to the aim of learning can be effectively and successfully.

Concept of Draw Label Caption (DLC)

The concept of Draw Label Caption (DLC) is described in the following explanation.

a. Draw

Peha (2003, p.47) states that draw is making a quick pencil sketch of your scene. Based on the quotation above, it can be inferred that draw is the activity make a picture with using a tolls with the certain object and purpose.

b. Label

Peha (2003, p.47) defines label as create a one or two word text label for each item in your drawing. From the quotation above, the writer assumes that label is a word or more that can be used to give a name for an object which wants to describe.

c. Caption

In Oxford Advanced Learner's Dictionary (2000, p.185) the word caption is defined as "words that are printed underneath a picture, cartoon, etc. that explain or describe it." Based on the quotation above, it can be inferred that caption is a phrase that can be the main or topic of the paragraph.

From the explanation about the definition of each words Draw-Label-Caption (DLC) technique above, can be explained of the theory of Draw-Label-Caption (DLC) technique.

According to Michael Hutagulung in www.englishadvantage.info/lessonplans/draw-label-caption "Draw Label Caption (DLC) technique is the both a lesson plan and pre-writing technique that can help the students brainstorm before writing a functional story or a personal narrative. It can also be used to introduce 
new vocabulary or review vocabulary. The basic technique is those students draws a picture, then label everything in the picture and then give an overall caption or summary of what is happening in the picture." Moreover Peha (2003, p.47) explains that "drawing for writing is a little different than normal drawing because it has a purpose."

From the various definition above, the writer can conclude that Draw Label Caption (DLC) technique is the technique that can help the students capture a scene and focus on important details about the writing their event or activity. Because the students in this technique have three steps and every step has a purpose in writing process.

Concept of Drill Technique

Frackney (1953, p.3) said that Drill is a group creativity technique by which a group tries to find a solution for a specific problem by amassing a list of ideas spontaneously contributed its members. Drill is being more effective at generating greater quantity and quality of ideas than individuals working.

Drill is mechanical ways if getting students to demonstrate and practice their ability to use in specific language items in controller manner This technique can make students be easier to understand and mastered Descriptive Text namely; formatting, punctuation, generic structure, content, and grammar. (Harmer, 2003, p.3).

Based on the definitions above, can be concluded that Drill technique is technique or procedure that can make students demonstrate and practice their ability to find a solution for a specific problem by amassing a list of ideas spontaneously.

\section{METHODS}

According to Sugiyono $(2003,183)$ research design is all processes that are needed on the planning and doing the research. Research design that will be used in this research is quasi experimental design. In quantitative research, the aim is to determine the relationship between one thing (an independent variable) and another (a dependent or outcome variable) in a population. Quantitative research designs are either descriptive (subject usually measured once) or experimental (subject measured before and after a treatment). A descriptive study establishes only associations between variables. An experiment establishes causality.

This research was an experiment research which would be conducted a quantitative; it would be held at Civil Engineering study program of Muhammadiyah University of Metro. The research will investigate the second semester in the academic year 2016/2017. This study applies one pre-test and one post-test in which three times of treatment is given between them. The researcher uses the test to do the research first. From this instrument, the researcher wants to know about the students' writing ability in descriptive text. The process of the test is at the first the researcher asks the students to write descriptive text that consist of some parts based on the theme. The students do the task to make descriptive text. The design can be presented as follows: 
Table 2: Pre-Test, Post-Test Control Group Design

\begin{tabular}{|l|l|l|l|}
\hline Group & Pre-test & Treatment & Post-test \\
\hline Experimental & T-1 & X1 & T-2 \\
\hline Control & T-1 & X2 & T-2 \\
\hline
\end{tabular}

(Adapted by Karwono, 1992, p.77)

Note :

T1 :Pre-test

X1 : Treatment with DLC

X2 : Treatment with Drill

T2 : Post-test

The design of research more detail will researcher figure out in figure below:

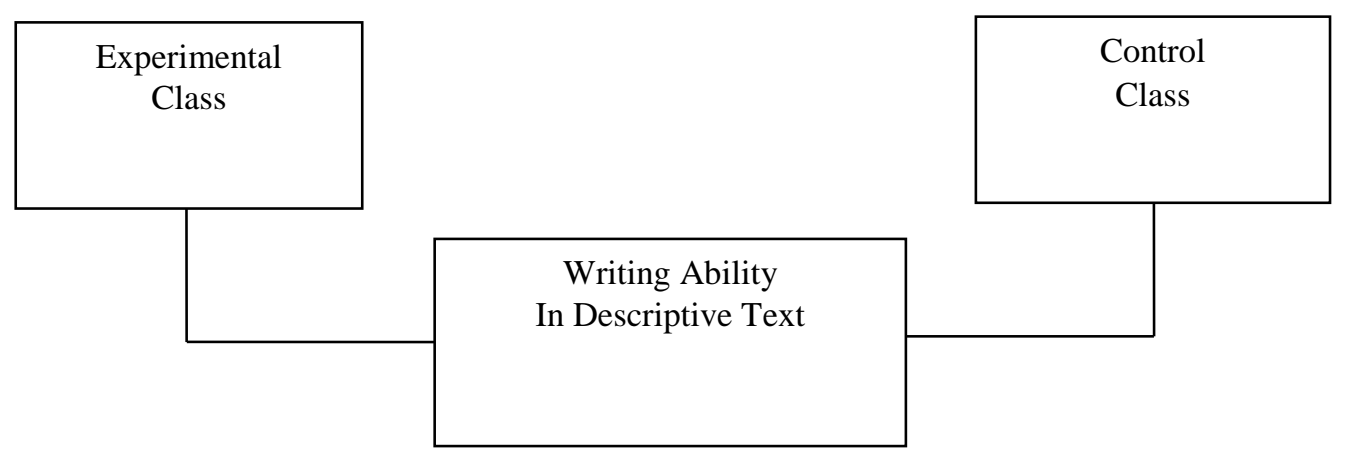

Figure 1: The Research Design

The first action of the research gives the pretest to experimental and control class together. After finished give the pretest, the next action is commencing the treatment to the experimental class. The experimental classes given for treatment by DLC and Drill treatment were given in the next day. Having finished conducting the treatment, the next step is giving the post test to the experiment group and control group.

\section{FINDINGS AND DISCUSSION}

Collecting data is the most important step in conducting the research. In this case, the researcher has measured the validity and the reliability of the test instruments. Then, the researcher used test instruments as data collecting method. Hence, the researcher explained or described about the result of the data collecting method which consists of pre-test, treatment and post-test.

\section{Result of Writing Descriptive Text Ability in Pre Test}

Researcher administered a pretest to both sample groups before giving the treatments. The researcher administered the pretest on February, $19^{\text {th }} 2017$ to experiment class while to the control class on February $17^{\text {th }}, 2017$. The pretest was given to students which consisted of 35 students in class A and 35 students in class B. 
Table 3: Distribution Frequency of Students' Writing Ability in Pre test at Experimental Class

\begin{tabular}{|l|c|c|c|}
\hline No. & Interval & Frequency & Frequency of Absolute \\
\hline 1. & $36-41$ & 4 & $8 \%$ \\
\hline 2. & $42-47$ & 5 & $12 \%$ \\
\hline 3. & $48-53$ & 10 & $32 \%$ \\
\hline 4. & $54-59$ & 7 & $20 \%$ \\
\hline 5. & $60-65$ & 5 & $16 \%$ \\
\hline 6. & $66-71$ & 4 & $12 \%$ \\
\hline \multicolumn{2}{|c|}{ Total } & 35 & $100 \%$ \\
\hline
\end{tabular}

Based on the distribution frequency above, in experimental class the highest score is 71 , it was in frequency of absolute $12 \%$ and the lowest one is 36 , it was in frequency of absolute $8 \%$. A mean of the data in experimental class is 54,1 and the standard deviation is 8,66.

Meanwhile, the highest score in the control class is 71, it was in frequency of absolute $4 \%$ and the lowest one is 36 , it was in frequency of absolute $12 \%$. A mean of the data in experimental class is 51,7 and the standard deviation is 7,93 . From the data above, it is known that most of them have limited vocabulary mastery.

Result of Draw Label Caption (DLC) Treatment

In this research, the researcher gave three treatments, and each treatment consists of one topic. In experimental class, for the first treatment, the highest score was 70 and the lowest score was 50. In the second treatment, the highest score was 75 and the lowest score was 50. In the third treatment, the highest score was 77 and the lowest score was 62. The total score from the first treatment until the third treatment in experimental class was 4421 .

Result of Drill Treatment

In the other hand, in control class the total score from the first treatment until the third treatment was 4979. For the first treatment, the highest score was 70 and the lowest score was 55. In the second treatment, the highest score was 72 and the lowest score was 60. In the third treatment, the highest score was 77 and the lowest score was 65.

Result of Writing Descriptive Text Ability in Post-Test

The posttests were given after the researcher gave the treatments to experimental and control groups. The post-test was applied to know the students' writing ability after they received the treatments. The purpose of the test is to know the significant different result between the experimental and control classes. The researcher administered the post-test in experiment class on March $5^{\text {th }}, 2017$. While, in control class on March, $3^{\text {rd }} 2017$.

Table 4: Distribution Frequency of Students' Writing Ability in Post test at Experimental Class

\begin{tabular}{|l|c|c|c|}
\hline No. & Interval & Frequency & Frequency of Absolute \\
\hline 1. & $65-68$ & 4 & $8 \%$ \\
\hline 2. & $69-72$ & 6 & $16 \%$ \\
\hline 3. & $73-76$ & 9 & $28 \%$ \\
\hline 4. & $77-80$ & 8 & $24 \%$ \\
\hline 5. & $81-84$ & 5 & $16 \%$ \\
\hline 6. & $85-88$ & 3 & $8 \%$ \\
\hline \multicolumn{2}{|c|}{ Total } & 35 & $100 \%$ \\
\hline
\end{tabular}


From the distribution frequency above, in experimental class resulted 88 for the highest score which was in frequency of absolute $8 \%$ and 65 for the lowest one which was in frequency of absolute $8 \%$. And it had a mean 76,42 and standard deviation 5,55 .

Table 5: Distribution Frequency of Students' Writing Ability in Post test at Control Class

\begin{tabular}{|l|c|c|c|}
\hline No. & Interval & Frequency & Frequency of Absolute \\
\hline 1. & $65-67$ & 5 & $12 \%$ \\
\hline 2. & $68-70$ & 8 & $24 \%$ \\
\hline 3. & $71-73$ & 9 & $28 \%$ \\
\hline 4. & $74-76$ & 6 & $20 \%$ \\
\hline 5. & $77-79$ & 4 & $12 \%$ \\
\hline 6. & $80-82$ & 3 & $4 \%$ \\
\hline \multicolumn{2}{|c|}{ Total } & 35 & $100 \%$ \\
\hline
\end{tabular}

Meanwhile, in control class the result was 82 for the highest score which was in frequency of absolute $4 \%$ and 65 for the lowest score which was in frequency of absolute $12 \%$. And it had a mean 72,24 and standar deviation 4,05.

As described in the previous chapter, the purpose of this study is to know the different result of using Draw Label Caption (DLC) and Drill Technique toward students' writing ability in descriptive text, and to know which one is more effective toward the students' students' writing ability between using Draw Label Caption (DLC) and Drill Technique. To clarify the purpose of this study, the researcher used writing tests (which is applied in pre and post test) as a research instrument, and the average score of pretest and posttest for each class using Draw Label Caption (DLC) and Drill Technique are compared to find out the advantages of both score.

The calculation result on the value of the pretest and posttest score in each class (experimental and control) showed that the distribution is normal. In addition, the calculation of t-test in the experimental class for pre test showed that the probability is less than the level of significance $(0,05=2,02)$ and $(0,01=2,7)$ because the probability is less than the level of significance $(1,02<2,02<2,7)$ there is no difference or in other words null $\left(h_{0}\right)$ hypothesis is accepted. For the calculation of posttest, it showed that the probability is higher than the level of significance $(3,04$ $>2,02>2,7)$ there is difference or in other words null hypothesis is rejected. It showed that there are some different results between pre and post test score in experimental class and control classes. Additionally, the change of students' posttest score is higher than their pre-test value especially in experimental class which using Draw Label Caption (DLC). It means that, Label Caption (DLC) is more effective media than Drill media since it may improve the students' writing ability in descriptive text.

\section{CONCLUSION}

After the researcher finished the research and analyzed the data, then concluded based on the theoritical knowledge and the result of data analysis. it can be concluded that there is any different result of student's writing ability in descriptive text using Draw Label Caption (DLC) and Drill Technique at The second semester of Civil Engineering students of Muhammadiyah University of Metro in Academic Year 2016/2017. Then, Draw Label Caption (DLC) is more 
effective than Drill Technique in developing the writing ability. The conclusion above can be shown based on the findings of data analysis as follows:

From the analysis of the data, there are different results of Draw Label Caption (DLC) and Drill Technique toward students' writing ability in descriptive at the second semester of Civil Engineering students of Muhammadiyah University of Metro in Academic Year 2016/2017. It is proved that based on the result of $t_{\text {test }}$, where $t_{\text {count }}=3,04$ is higher than $t_{\text {table }}=2,68$ on the criterion 0,01 . It means that the students' writing ability will be increased if the teacher uses Draw Label Caption (DLC) technique in his/her learning process. So, the researcher concludes that there are different results of using Draw Label Caption (DLC) and Drill Technique toward students' writing ability in descriptive text at the second semester of Civil Engineering students of Muhammadiyah University of Metro in Academic Year 2016/2017.

Draw Label Caption (DLC) Technique is more effective than Drill Technique toward students' writing ability in descriptive text at the second semester of Civil Engineering students of Muhammadiyah University of Metro in Academic Year $2016 / 2017$. It can be seen from the result of $t_{\text {test}}$, where $t_{\text {count }}=3,04$ is higher than $\mathrm{t}_{\text {table }}=2,01$ on criterion 0,05 and the average score of the students who were taught by using Draw Label Caption (DLC) Technique is higher than Drill Technique. So, it is clearly seen that the hypothesis $\mathrm{H}_{1}$ in this research is accepted. The improvement of the students' writing ability in descriptive text by using Draw Label Caption (DLC) Technique is higher than Drill Technique. Besides, the students are more motivated in the learning process and they are interested in developing paragraphs especially by producing many new vocabularies that have gotten from labeling the picture, hence the teacher is also easier to apply the technique for the students in active learning.

\section{REFERENCES}

Cresswell, W. J. (2005). Educational Research: Planning, Conducting, and Evaluating Quantitaive and Qualitative Research. Upper Saddle River, NJ: Pearson Merril Prentice Hall

Frackney (1953). An introduction to foreign language learning teaching. England: Longman.

Ghaith, Ghazi (2002). The Problem of Teaching Writing. American University of Beirut (online). Available at: http://nadabs.tripod.com/writing/.

Harmer, Jeremy (2003). An introduction to The Practice of English Language Teaching. Malaysia: Longman

Oshima, Alice (2007).Introduction to Academic English. New York: Longman

Peha, Steve (2003).The Writing Teacher's Strategy Guide. New York: Longman.

Rahayu, A.(2014). The Comparison of Using Draw Label Caption (DLC) and Think Pair Share (TPS) Technique toward Students Writing Ability in Descriptive Text at the Students of SMA N 1 Seputih Banyak.

Sari, Linda (2015). The comparison of using draw label caption (DLC) and drill technique toward writing ability in descriptive text at the students of SMA N 1 Pekalongan academic year 2014-2015.

Setiyadi, Bambang (2007). Teaching English as a Foreign or Second Language. United States of America: the University of Michigan Press.

Sugiyono (2013). Metode Penelitian Pendidikan Pendekatan Kuantitatif, Kualitatif, dan R\&D. Bandung: Alfabeta. 
Sulistiani, E (2013). The Comparison of Using Draw Label Caption (DLC) and Round Table Technique toward Students Writing Ability in Descriptive Text at the Students of SMA N 1 Rumbia.

Thresia, Fenny (2012). Handout Writing. Metro: UMM Press. 